University of Nebraska - Lincoln

DigitalCommons@University of Nebraska - Lincoln

To Improve the Academy

Professional and Organizational Development

Network in Higher Education

1998

Faculty Developers as Change Agents: Transforming Colleges and Universities into Learning Organizations

Sondra K. Patrick

James J. Fletcher

Follow this and additional works at: https://digitalcommons.unl.edu/podimproveacad

Part of the Higher Education Administration Commons

Patrick, Sondra K. and Fletcher, James J., "Faculty Developers as Change Agents: Transforming Colleges and Universities into Learning Organizations" (1998). To Improve the Academy. 411.

https://digitalcommons.unl.edu/podimproveacad/411

This Article is brought to you for free and open access by the Professional and Organizational Development Network in Higher Education at DigitalCommons@University of Nebraska - Lincoln. It has been accepted for inclusion in To Improve the Academy by an authorized administrator of DigitalCommons@University of Nebraska - Lincoln. 
Patrick, S. K., \& Fletcher, J. J. (1998). Faculty developers as change agents: Transforming colleges and universities into learning organizations. In M. Kaplan (Ed.), To Improve the Academy, Vol. 17 (pp. 155-170). Stillwater, OK: New Forums Press and the Professional and Organizational Development Network in Higher Education. Key Words: change strategies, faculty attitudes, faculty development role, higher education environment, leadership, organizational development.

\section{Faculty Developers as Change Agents: Transforming Colleges and Universities into Learning Organizations}

\section{Sondra K. Patrick}

George Washington University

\section{James J. Fletcher}

George Mason University

In the face of demands for institutional restructuring and competition from new internet-based degree programs, the authors argue that campus-based colleges and universities may continue to serve their students well by becoming effective learning organizations. They argue, further, that faculty developers are in the best position to help their institutions become learning organizations. After describing the features of learning organizations as articulated in the work of Peter Senge, the authors reinterpret Senge's theory to make specific application to academic settings. Concrete suggestions are provided for faculty developers to assist in transforming their institutions.

Many colleges and universities are in the midst of restructuring projects similar to the massive restructuring that has occurred in 
American industry during the last decade. For most industrial organizations restructuring has resulted in downsizing with the goal of increased productivity and profits. For colleges and universities, however, restructuring has meant something different: a response to legislative mandates and public outcries to operate more efficiently and to be more responsive to constituents' needs. A responsive academic culture, to people outside the academy, means ensuring that graduates have the requisite skills for the workplace and understand how to function in a highly diverse and technologically demanding world. Legislators are also concerned about how faculty at publicly supported institutions spend their time and want assurances that faculty accomplishments are closely aligned with institutional missions and community needs. In addition, local and regional corporations have pressed institutions to ensure that faculty research agendas focus on resolving problems that are important to local industry and local communities and not just to individual faculty interests. As one author has expressed the current problem facing institutions, "virtually every other sector of American society has gone (or is going) through a transformation that makes funding contingent on the delivery of valued outcomes. The public we serve sees us, and our work, through that new lens; it will not much longer fund us as a self-evident good" (Plater, 1995, p. 24).

Perhaps the most significant threat to business as usual in higher education stems from increased competition. In a recent edition of the AAHE Bulletin (1998), Ted Marchese describes the extent of the competition that has arisen in just the last couple of years. While higher education has contended for years with proprietary institutions and with institutions offering distance learning options in competition with regional institutions, the scope of the current challenge is dramatically different today because of the emergence of information technology and, especially, the growth of the World Wide Web. According to Marchese the University of Phoenix has come "from next to nothing a handful of years ago...[to] 48,000 degree-credit students at 57 learning centers in 12 states" (Marchese, 1998, p. 3). Even more challenging is the formation of Western Governors University (WGU). This is a cooperative venture involving 17 governors and 14 business partners, including leading high technology companies. 
What is most significant about this venture is that 'WGU won't employ teaching faculty, develop courses, or deal in credit hours; its online academic content will come from a range of qualifying providers (colleges or businesses, here or abroad), and all degrees will be competency-based"(Marchese, 1998, p. 4). For several years academe has looked over its shoulder at emergent "corporate universities" established by such companies as McDonald's; other corporations are now developing significant learning options that are not targeted exclusively at their own employees. These include IBM, Jones (of the cable industry), and Microsoft.

The message is that colleges and universities no longer have a monopoly in the higher education knowledge trade. Although faculty bristle at the idea that they deal with a product and that their students are consumers, students increasingly see themselves in these terms. Already, many of our students are willing to walk away from courses not to their liking even though it means loss of money or academic credit. If the present is an indicator of the future, we can be sure that they will be willing to support those venues that serve their needs even if they are outside the academy, such as proprietary institutes or private corporate universities. As Carol Twigg, Vice President at Educom, notes in her response to Marchese's article, "what was once a competitive advantage - the physical concentration of intellectual resources on a residential campus-is no longer a critical differentiator" (Marchese, 1998, p.9). One of the challenges for colleges and universities will be to demonstrate that they can differentiate themselves from the emerging competition and to sell this to their constituents. What students seem to be looking for are institutions that are student focused and ready to deal with them on an individualized basis.

It appears that determining how to restructure institutions to meet most effectively the needs of students and faculty in the future will be the subject of debate for some time to come. We believe that lessons learned from the outcomes assessment movement and the emergence of technology both offer clues to a promising model. Assessment required faculty to think differently about their courses and curricula. Instead of focusing in an input fashion on the topics and texts for their courses, they were required to ask: What do I want to accomplish? What do I want my students to know and/or be able to do when they 
complete this course or this curriculum? The questions of assessment shifted the focus from the teacher to the student, from instruction to learning. Technology has brought a whole new language to higher education with terms like "hypertext," "hyperlearning," and "asynchronous" instruction. The range of options already available to us, with more being developed, requires again that we rethink the way students and faculty interact and revise our notions of appropriate learning environments. The impact of email, list-serves, and webbased class fora is dramatic. These techniques increase the role of the student both in setting the class agenda and in helping fellow students understand the salient points of the lecture or course. Because learning is social and interactive, peers can play these valuable roles. While retaining control of the course content, the faculty member is no longer the center of attention. As more emphasis is placed on student learning, the significance of the faculty member as the all-knowing provider of information is lessened, and the faculty member is better viewed as guide, coach, and mentor.

At two recent conferences, Faculty Roles and Rewards, January, 1998, and its National Conference in March, 1998, the American Association for Higher Education (AAHE) focused considerable attention on the theme "taking learning seriously." We believe that, because it is student centered, focusing on learning offers great promise for colleges and universities as they attempt to address current challenges. However, the traditional organizational structure in the academy supports a reward system more focused on faculty professing than on students learning. To meet the programmatic needs of an increasingly diverse student population, institutions will have to create an environment that focuses on students as individuals. This requires more flexibility and adaptability than most colleges and universities have exhibited. Institutional reorientation can only be accomplished if all groups within the institution agree on a common set of goals and the means to achieve them. In other words, colleges and universities must themselves become what Peter Senge (1990) calls a learning organization. The key features of learning organizations are: shared ideals, collaboration, flexibility, and reflection. These features are not easily achieved in most academic settings. In our judgement signifi- 
cant changes must occur before higher education institutions can become "learning organizations."

Where learning organizations depend on shared visions and loyalties, the current reward structure encourages faculty to work autonomously, directing their loyalties primarily to national, discipline-based organizations. The reason for this is not hard to discern; it is recounted in Bowen and Schuster's (1986) landmark work, American Professors: A National Resource Imperiled. In the mid 1970s and early 80s institutions of all kinds (liberal arts colleges to comprehensive universities) began to mimic research institutions by making research the primary basis for faculty reward. They could do this because of the glut of research-oriented Ph.D.s available. As a corollary, the role of teaching in 1986 as a means to securing promotion and tenure was diminished. Faculty have increasingly placed their time and effort on those projects that institutions have come to reward, namely, grants and publishable research. The push to publish research has resulted in an explosion of narrow academic specializations within the disciplines making it increasingly difficult for colleagues to communicate even within disciplines much less across them. As Plater (1995) puts it, "faculty, like physicians, have ignored primary care in favor of personal, specialized interests" (p. 23). The late Ernie Boyer (1990) sought to lessen the impact of the current reward system by urging that the concept of scholarship itself be broadened beyond the traditionally acknowledged scholarship of discovery.

If colleges and universities are to become learning organizations, the current reward systems must be rethought. But more is required. Higher education institutions must develop supportive cultures; create environments that value risk-taking; reward innovative exploration and implementation; and encourage collaboration, trust, and a sense of connectedness to institutions and communities. We believe that faculty developers are ideally suited to play a major role in creating such an environment. To do so they must become change agents on their campuses. In the sections that follow, we discuss the features of learning organizations and then suggest some ways in which faculty developers can play a key role in transforming colleges and universities into learning organizations. 


\section{What is a Learning Organization?}

According to Senge, learning organizations require a "shift in mind-from seeing ourselves as separate from the world to connected to the world, from seeing problems as caused by someone or something 'out there' to seeing our own actions create the problems we experience" (pp. 12-13). Whether the organization is IBM, Microsoft, Proctor and Gamble, NBC, or a college or university, the idea is that helping individuals see themselves connected to an organization is the key ingredient for keeping an organization vibrant, responsive, and flexible enough to meet the needs of a rapidly changing society. In his text, The Fifth Discipline, Senge describes five components of a learning organization. Using the headings of Senge's five components, we provide some concrete examples (in italics) of what needs to be done within the academy to develop higher education institutions as learning organizations.

1. Systems Thinking is the process of thinking about a system as a whole. It contains a "conceptual framework" that provides connections between units within an organization, integrating knowledge and tools for more effective problem solving. This component includes the processes of reevaluation and reflection. It involves the ability to see connections and relationships within an organizational structure such as the link between the number of hours worked and the need to increase productivity; the number of sale items sold and the need to raise profit margins; or the relationship between collaborative teaching strategies and ways to enhancing learning. In contrast to systems thinking, the traditional academic framework consists of distinct disciplines, specialized research tools, and isolated learning environments. To develop systems thinking, institutions of higher education need to create or recover a common language focused on, for example, pedagogy, institutional missions, institutional goals, and, perhaps, the state of higher education itself in the information age. For institutions to function as true learning organizations, each unit must see itself as part of the whole. This requires that institutions develop ways to share information across units and 
disciplines and obtain feedback about the processes they implement. At many institutions, the only place where features of learning organization are found are in specially developed schools, such as New Century College at George Mason University, the Cyberschool Initiative at Virginia Tech, or the Learning Innovation Center at the University of Wisconsin.

2. Personal Mastery involves helping individuals achieve their maximum potential as experts in their fields or at their crafts. Being an expert, in this sense, means the ability to contribute to the advancement of a field or organization in creative and innovative ways by addressing new or emerging problems. Each type of organization has a different set of individual experts, e.g., innovative software developers at Microsoft, highly skilled accountants at Price Waterhouse, and highly trained medical specialists at General Hospital. In the academy, faculty are recognized as experts in their specific disciplines and sub-disciplines, but this kind of localized, disconnected specialization frequently results in isolation. Faculty working in isolation do not have a sense of contributing directly to an institution's goals. In many cases, these sub-disciplines or areas of specialization are so narrow that communication among colleagues even within a discipline becomes difficult. Certainly, scholarship that results in new knowledge is a critical component of the work of an academician, but it is not the only role. The academy's responsibilities are broader, encompassing also the scholarship of integration, application, and teaching, as well as discovery (Boyer, 1990). To help foster a learning organization, faculty need to reassess their relationship to their institutions and communities by becoming actively engaged in campus dialogues about the missions and goals of the institutions and communities they serve, sharing pedagogical expertise with colleagues, and exchanging disciplinary expertise in interdisciplinary teaching and research settings.

3. Mental Models refer to the culture and underlying assumptions that influence how an organization's personnel approach their work, and how they understand their work in relation to society as a whole. These models identify and define how tasks are completed; the degree to which innovation and creativity can be 
valued to solve problems; how employees feel about themselves in relation to the organization; and how they relate to peers, clients, or customers. The traditional academic culture fosters autonomy, using a reward system that encourages specialized research based on agendas set by faculty members. There is no real incentive to contribute to community building. But institutional success in an age of increasing competition will require that faculty members examine their assumptions about academic life and undertake a broader range of activities that support institutional and community goals. This change will not happen unless institutions create structures that foster collaboration across disciplines in teaching, research, and community service and broaden the reward system to more accurately reflect the work of faculty today.

4. Building a Shared Vision involves the collaborative creation of organizational goals, missions, identity, and visions that are shared and owned by each member of the organization. Senge's model is built on the idea that no one person has all the answers. Instead, answers come from teamwork, making each individual's contribution an integral part of the organization's success or failure. For the most part, there is not a shared institutional vision within the academy; at best there are departmental or disciplinary visions. Shared visions need not be based on intellectual constructs or research but may be developed around such issues as the improvement of student learning; the integration of technology and knowledge; the advancement of interdisciplinary knowledge; the creation of an intellectual community; and the development of effective partnerships among academic institutions, industry, and communities. These issues are at the heart of the work of faculty development.

5. Team Learning encompasses each component mentioned above and emphasizes the importance of creating more opportunities for individuals within an organization to work and learn together in an environment that supports and encourages collaboration. Individuals are given the security to create, fail, and create again. Team Learning is not a typical characteristic of academic settings. Institutions can provide more opportunities for collaborative 
experiences through such activities as interdisciplinary team teaching and research, cooperative learning, interactive group learning, and building learning communities for teaching and research with colleagues and students. In doing this, they must ensure individuals are not penalized for undertaking these roles.

Each component shifts the emphasis away from isolated, discipline-specific thinking to interdisciplinary, shared thinking characteristic of learning organizations. The learning organization model emphasizes the value of all members of an organization and the importance of being flexible and creative in today's rapidly changing environment.

\section{What Makes a Learning Organization Successful?}

Some of the best and most readily available examples of the learning organization model can be found in business and industry. To apply Senge's model to higher education, we consulted several experts to discover what features they felt were essential to successful implementation. Peters \& Waterman (1982) in their text, In Search of Excellence: Lessons from America's Best-Run Companies, report that successful organizations treat people (customers/workforce) decently, provide the support needed for employees to do a good job, and give praise often. W. E. Deming (1986) emphasizes the value of building supportive cultures in order to achieve the ultimate goal of "quality." Harvard Business School's Rosabeth Moss Kanter and London Business School's Charles Handy add some related features. Kanter (1995) says that "Organizations which are winning the new game are more focused, fast, flexible and friendly" (p. 76). Similarly, Handy (1995) lists "curiosity, forgiveness, trust and togetherness" as essential qualities of successful learning organizations. The features these experts identify as essential for developing successful learning organizations can be combined into three broad characteristics that we believe are appropriate for the academic culture:

1. Develop supportive cultures where collective recognition, friendliness, and sharing are norms in contrast to the isolation and 
autonomy characteristic of contemporary academic settings. This requires that faculty and administrators collectively develop institutional missions and goals. In the current context it demands a clear understanding both of the challenges facing higher education and of how these challenges will impact individual institutions.

2. Create an environment that values improvement, innovation and curiosity, and which recognizes that improvement involves both failures and successes. This feature relates closely to the role of faculty developers within the academy. Risk taking is necessary, especially where the use of new technology and active learning teaching strategies are concerned; but risk taking is not congruent with a reward structure that measures contributions with a single yardstick.

3. Encourage collaboration, trust, and a sense of connectedness. For the academy, this would mean fostering a sense of connectedness across departments/units, academic disciplines, schools, and, especially, among faculty from disparate academic traditions. At most academic institutions, collaboration and interdisciplinarity are not encouraged or rewarded so they are seldom considered worth time and effort by faculty.

\section{Faculty Developers as Change Agents}

The three characteristics summarized above definitely hint at what separates current academic culture from a learning organization culture. Below we will provide some concrete examples of how faculty developers can help institutions realize the three characteristics outlined above.

First, let us consider the role that faculty developers can play in helping institutions foster a more supportive and collaborative culture. In our judgement the place to start is to look at the challenges facing higher education and, in light of those challenges, to reflect on the institution's missions and goals. This task cannot be accomplished by either the administration or the faculty working alone. It requires what Charles Handy (1989) calls a "culture of consent" (p. 162) linking change to collaborative agreement. Since most faculty developers come from the ranks of the faculty, they are well positioned to serve 
a mediating role between the faculty and administration. The first task is to ensure that the campus community is aware and current concerning the national debate about the future of higher education. In our experience, most faculty remain current in their disciplines as it relates to their teaching and research, but they have very little awareness of the context in which higher education is currently operating. Few faculty we have spoken to read the Chronicle of Higher Education or Change or attend national meetings such as those sponsored by AAHE or the Association of American Colleges and Universities (AAC\&U). Faculty, therefore, lack the proper focus to initiate or support changes designed to meet higher education's obligations to the future. Administrators, assuming that they are aware of the current context (which may be a large assumption in some quarters), cannot, in Handy's terms, "command" the appropriate direction.

What concrete actions can faculty developers engage in to serve a mediating role in an ongoing discussion of an institution's mission and goals? One activity is to sponsor regular fora that bring administrators and faculty together to discuss critical issues facing higher education. The key to the success of these events is to make sure that the administrators attending are high ranking and that they address very concretely the way they see a matter of national debate affecting the local institution. At our institution, the most heavily subscribed faculty development events have been those at which the President, the Provost, or one of the deans agreed to participate in an open forum to discuss the priorities of academic life and to consider the impact of issues like post tenure review.

The rapid expansion in the use of email, list-serves, and web-based fora is an alternative way to initiate or to maintain campus discussions of matters of national import and to encourage faculty to reflect on how these issues might affect their professional lives. While faculty developers will not set institutional goals, they can insist that faculty and administrators jointly set goals for academic life to meet society's expectations. Participation in these activities contributes to systems thinking by focusing on institutional missions and goals.

Second, how can faculty developers influence the creation of an environment that rewards improvement, innovation, and curiosity? Clearly, faculty developers cannot change the conditions shaping 
faculty lives, nor is it in their power to change the reward structure in place at most American colleges and universities. However, faculty developers are in a position to judge whether the expectations are commensurate to the rewards and to initiate a campus discussion of their appropriateness. Ideally, such a discussion would also involve the same high ranking administrators who engaged in fora concerning missions and goals.

There are also some concrete actions that faculty developers can undertake to help faculty cope with the pressures of academic life. For example, junior faculty are especially in need of support. There are two types of activity that will benefit junior faculty. The first should occur very early, for example, at a new faculty orientation. Junior faculty need to know very plainly the reality of academic life at a given institution. Faculty developers are in a position to know and to relate the current expectations for renewal and promotion and tenure. It should be clear that the reality may not coincide with the rhetoric at an institution and fairness demands that new faculty have an opportunity to learn what they need to do to be successful. In addition to knowing what the standards are, faculty need to know how those standards will be interpreted. For example, our institution requires that faculty be good or excellent teachers. Faculty were troubled that the only measure of teaching seemed to be the mandated student course evaluations. To generate additional measures, staff from the Provost's office collaborated with the Committee on Effective Teaching (a faculty development body) to develop Guidelines for the Peer Review of Teaching. These Guidelines were intended to assist academic units in systematically and uniformly gathering data about a colleague's effectiveness as a teacher. The Guidelines had the added benefits of focusing attention on student learning and serving as a catalyst for open dialogue about pedagogical issues among faculty. When peer review is done well, Boyer's (1990) assertion that teaching is a form of scholarship can be affirmed.

Independent of the evaluation of teaching, faculty developers can help to change an institution's environment by aggressively pursuing their traditional role in the support of teaching. In particular, faculty need assistance in attending to learner-centered as compared to instructor-centered environments. Although a significant body of litera- 
ture about the value of learner-centered environments is now available (Bruffee, 1993; Davis, 1993; Halpern et al., 1994; Johnson, Johnson, \& Smith, 1991; Meyers \& Jones, 1993), it is easier to be convinced by the arguments than to accomplish it in fact. Workshops on cooperative learning techniques and the use of groups in classroom settings will help faculty focus on learning outcomes rather than on content to be covered. Technology is another area that faculty feel pressured to incorporate into their teaching. The use of technology, especially email and electronic class fora, has contributed to the focus on learners. Workshops that deal with "what works" and "what doesn't work," as well as strategies for managing time, intellectual property, webbased instructional environments, and computer-based library resources can help faculty negotiate these changes. These workshops also contribute to a common language of pedagogy and bring faculty together irrespective of discipline to deal with common issues. All of this helps to build a shared vision for the institution, its faculty, and its students.

Third, how can faculty developers encourage collaboration, trust, and a sense of connectedness? The workshops on pedagogy and the fora on missions and goals will already start the process of connecting people across disciplines and developing the conditions for trust to flourish. There is, however, another experience in academic life that encourages collaboration and meets the conditions of learning organizations as Senge described them, namely interdisciplinary teaching and learning. Because interdisciplinary teaching fosters a learnercentered learning organization, faculty developers would do well to contribute to the success of these programs on their campuses. The disciplinary focus tends to isolate both by the use of jargon and the singularity of method; in contrast, interdisciplinary experiences help both faculty and students recognize the incompleteness and limitations of what we know. In interdisciplinary teaching experiences, the faculty member usually does not view him/herself as the resident expert, and this contributes to a student-centered environment. Real-world problems do not respect the boundaries of our disciplines; interdisciplinary teaching allows us to model real-world problem solving. Finally, interdisciplinary teaching helps us demonstrate one of the goals of 
education: Learning is not the transmission of information but the locating, retrieving, understanding, and using of information.

Senge describes a learning organization as a "place where people are continually discovering how they create their reality. And how they can change it" (p. 13). Higher education is continuing to evolve as it responds to internal and external pressures to change. Senge's insights would suggest that as higher education evolves it should: broaden its expectations for success; recognize stages of academic development; and understand that, while there will always be lone researchers as part of the model for success, the isolated researcher disengaged from the campus community should not be the only, and for the future not even the best, model. Faculty developers should play an important role in bringing this evolution to fruition.

\section{References}

Bowen, H. R., \& Schuster, J. H. (1986). American professors: A national resource imperiled. New York: Oxford University Press.

Boyer, E. L. (1990). Scholarship reconsidered: Priorities of the professoriate. Princeton, NJ: The Carnegie Foundation for the Advancement of Teaching.

Bruffee, K. A. (1993). Collaborative learning: Higher education, interdependence, and the authority of knowledge. Baltimore, MD: The Johns Hopkins Press.

Davis, J. R. (1993). Better teaching, more learning: Strategies for success in postsecondary settings. Phoenix, AZ: Oryx Press.

Deming, W. E. (1986). Out of the crisis. Cambridge, MA: Center for Advanced Engineering Study, Massachusetts Institute of Technology.

Halpern, et al. (1994). Changing college classrooms: New Teaching and learning strategies for an increasingly complex world. San Francisco, CA: Jossey-Bass.

Handy, C. (1989). The age of unreason. Boston, MA: Harvard Business School Press.

Handy, C. (1995). Managing the dream. In S. Chawla \& J. Renesch (Eds.), Learning organizations (pp. 45-55). Portland, OR: Productivity Press.

Johnson, D. W., Johnson, R. T., \& Smith, K. A. (1991). Active learning: Cooperation in the college classroom. Edina, MN: Interaction Book Company.

Kanter, R. M. (1995). Mastering change. In S. Chawla \& J. Renesch (Eds.), Learning organizations (pp. 71-83). Portland, OR: Productivity Press.

Marchese, T. (1998). Not-so-distant competitors: How new providers are remaking the postsecondary marketplace. AAHE Bulletin, 50(9), 3-11.

Meyers, C., \& Jones, T. B. (1993). Promoting active learning: Strategies for the college classroom. San Francisco, CA: Jossey-Bass. 
Peters, T. J., \& Waterman, R. H., Jr. (1982). In search of excellence: Lessons from America's best-run companies. New York: Harper \& Row.

Plater, W. M. (1995). Future work: Faculty time in the 21 st century. Change, 27(3), 22-33.

Senge, P. M. (1990). The fifth discipline. New York: Doubleday.

Contact:

Sondra K. Patrick

Graduate School of Education and Human Development

George Washington University

2134 G Street NW

Washington DC 20052

(202) 994-5877

(202) 994-5870 FAX

kpatrickva@aol.com

James J. Fletcher

Deparment of Philosophy and Religious Studies

George Mason University

Fairfax, VA 22030

(703) 993-8774

(703) 993-1297 FAX

jfletche@gmu.edu

Sondra Patrick is Assistant Professor of Higher Education Administration. She teaches higher education administration and research methods courses at the Graduate School of Education and Human Development, George Washington University (Washington, DC). Her research focuses on institutional transformation, faculty development, and the effects of technology on learning. She holds a $\mathrm{PhD}$ in education from George Mason University (Fairfax, VA).

James Fletcher is an Associate Professor of Philosophy at George Mason University in Fairfax, Virginia. In addition to teaching philosophy, he has held a variety of administrative posts including: Assistant Provost, Dean for Undergraduate Studies, Associate Provost, and Director of the University Project on Teaching and Learning. He has been a frequent presenter on higher education issues at the American Association for Higher Education (AAHE), the Lilly Conference on Teaching, the American Educational Research Association, and the Association of Institutional Researchers. His teaching interests include bioethics, philosophy of art, and philosophy of technology. 